\title{
Seismic Explorations Conducted in Kyoto and Its Environs for Determining Shallow Subsurface Structure
}

\author{
Yoshimasa Kobayashi* and Tomoki Tsutsui \\ Geophysical Institute, Kyoto University, \\ Sakyo-ku, Kyoto 606, Japan
}

\begin{abstract}
Experiences of a series of seismic explorations conducted in Kyoto and its environs for investigating subsurface structures up to $1 \mathrm{~km}$ are summarized and discussed. Examples of explorations using power spectra or phase velocities of microtremors, the refraction method of various scales, the classical reflection method with the ray-tracing analysis, and the CDP method as well as a newly devised pseudo-reflection profiling (PRP) method are presented. The amount of labor and attainable resolution of the above methods are compared. The PRP method is efficient, since this is fairly high in resolution and can be applied for a wide area with relatively little effort.
\end{abstract}

\section{Introduction}

It has long been noticed in Japan since the 1923 Great Kanto earthquake that soft surface layers affect the characteristics of shaking on the ground surface strongly. Most densely populated city areas and important industrial areas are located in plains underlain by thick young deposits, and it is demanded to determine subsurface structure in those areas to assess strong shaking during future destructive earthquakes.

From the earthquake-prediction point of view, on the other hand, it is highly desirable to determine whether earthquake-prone active faults do or do not exist below soft deposits in such important areas, since buried faults may possibly have remained undetected in preparing active fault maps in 1980 which were based mainly on air-photos (Research Group for Active Faults in Japan, 1980).

In view of the situation above, we have conducted a series of seismic explorations of subsurface structure up to depths on the order of $1 \mathrm{~km}$ in soft-deposit areas near Kyoto, and accumulated experiences of application of various methods in varying situations. The seismic methods we refer to here are those of broad sense, i.e., not only active methods such as through seismic refraction or reflection surveys but also passive ones such as through measurements of microtremors or microseisms.

We summarize in this paper some examples of seismic explorations conducted mainly by our group in Kyoto and its environs and discuss various features of the results obtained with various procedures. Some results by other researchers are also referred to when necessary for discussion.

Received November 20, 1990; Accepted September 20, 1991

* To whom correspondence should be addressed. 


\section{Examples of Various Exploration Methods}

\subsection{Microtremors and microseisms}

We use the terminology of microtremors and microseisms in this paper for seismic noises with periods shorter and longer than about $2 \mathrm{~s}$, respectively. The former is likely generated by relatively near artificial sources while the latter by natural sources in long distances including surf on the beach. We will use, however, the term microtremors inclusively when discrimination between both kinds of seismic noises is not necessary and there is no risk for misunderstanding.

The measurement of microtremors or microseisms for the purpose of exploration of subsurface structures may be divided into 1) the measurement of their power spectra and 2) the array observation of their propagational characteristics. The former is simpler and easier than the latter in both data acquisition and data processing, since the vibrational characteristics of a site can be evaluated independently from those at other sites while in the latter every seismogram in an array must be treated on a common time base. It is natural therefore that the first procedure has been used more frequently in the early stage of microtremors investigations.

A very impressive example that this procedure is useful in judging the change in subsurface structure was demonstrated by Irikura and Kawanaka (1980). They measured microtremors at some ten stations with intervals of 50 to $100 \mathrm{~m}$ near Obaku, on the south-east margin of the Kyoto basin, by using seismometers of 1-s period and found that the (inverse) ratio of the power spectra of microtremors at a point to those at a reference point changed significantly across the Obaku fault (east side upthrown) bounding the basin (Fig. 1). They interpreted the result as an effect of the difference in velocities in underlying layers up to $200 \mathrm{~m}$ below the stations. Encouraged by their success, Imazumi and Kobayashi (1985) measured microtremors on the western margin of the Kyoto Basin by using seismometers of 2-s period. To elucidate the subsurface structure of the Kanegahara fault (west side upthrown) bounding the basin, they set 8 stations with intervals about $180 \mathrm{~m}$ covering the postulated fault location and confirmed that the peaks of the spectral ratios on the soft-deposit side (foot-wall side) of the fault to a reference station may be said significant considering the confidence intervals of the ratios as is discussed in a later section (Fig. 2).

A similar treatment is possible also for microseisms if only measuring systems are modified to cover a range of longer periods. Ohta and his colleagues have measured microtremors of 1- to 5-s periods, i.e. microseisms in this paper, systematically with an intention to investigate a correlation between site conditions and strong-motion characteristics (Ohta et al., 1978). Since the success of their studies, the measurement of microseisms has been rather popular in Japan as a means to survey subsurface conditions economically. Tsutsui and Kobayashi (1989) measured microseisms in the Hino River flat on the south-eastern coast of Lake Biwa on two parallel linear arrays of stations over several kilometers each to determine an approximate subsurface structure up to depths of about $1 \mathrm{~km}$ in the area by using horizontal-type seismometers with the period of $7 \mathrm{~s}$ and found a sharp change in microseisms spectra over the frequency band, 0.3 to $0.4 \mathrm{~Hz}$, across Hino River. This information was useful in deciding measuring lines and field parameters for succeeding reflection explorations. 

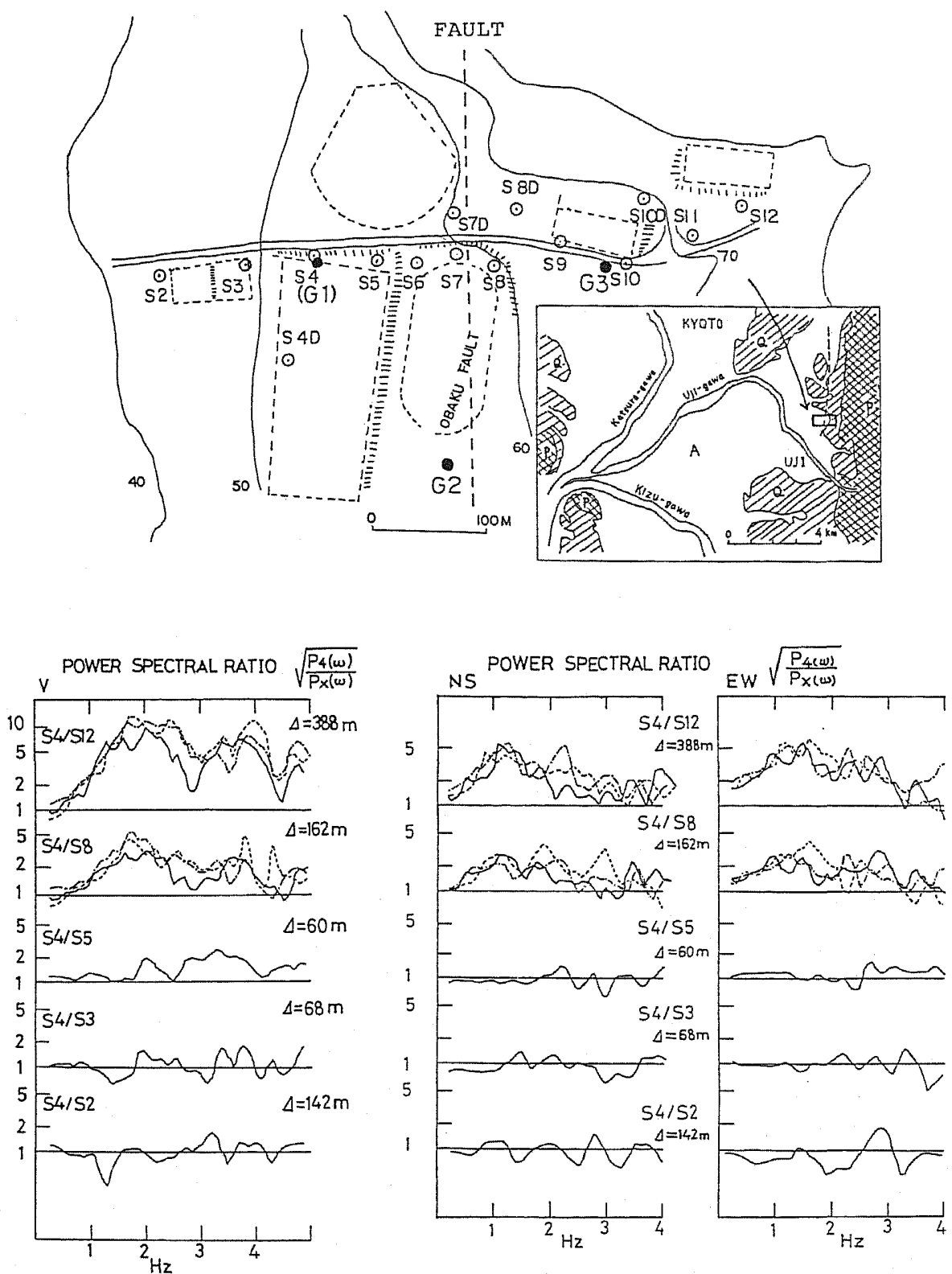

Fig. 1. Top: Observation points of microtremors across the Obaku fault. Bottom: Square-root ratios of power spectra at S4 to those at S2, S3, S5, S8, and S12 (after Irikura and Kawanaka, 1980). Solid, dashed and chained curves are the values obtained from repeated measurements with intervals of about $2 \mathrm{~h}$. Ratios S4/S12 and S4/S8 for sites 12 and 8 (hanging-wall side) are significantly larger than the ratios for other sites (foot-wall side).

Vol. 40, No. 1, 1992 


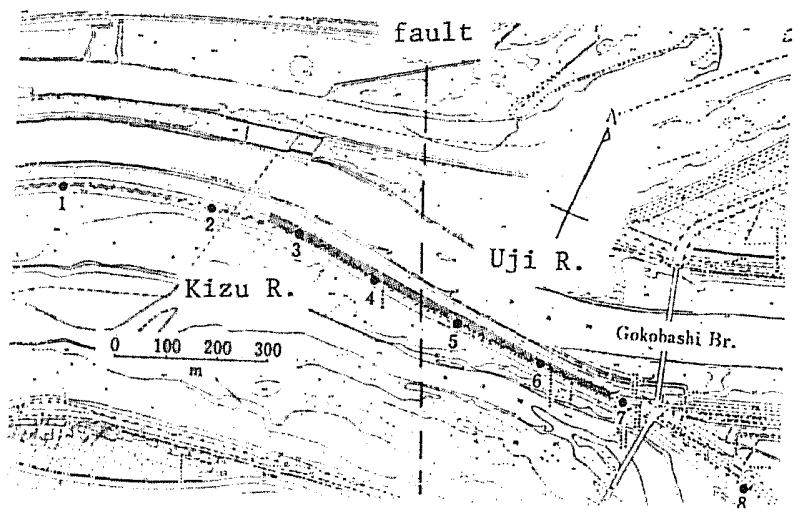

YWTNS SPECTRAL RATIO

95. OTH PERCENTILE CONFIDENCE INTERVAL DEGREES OF FREEDOM $=120$
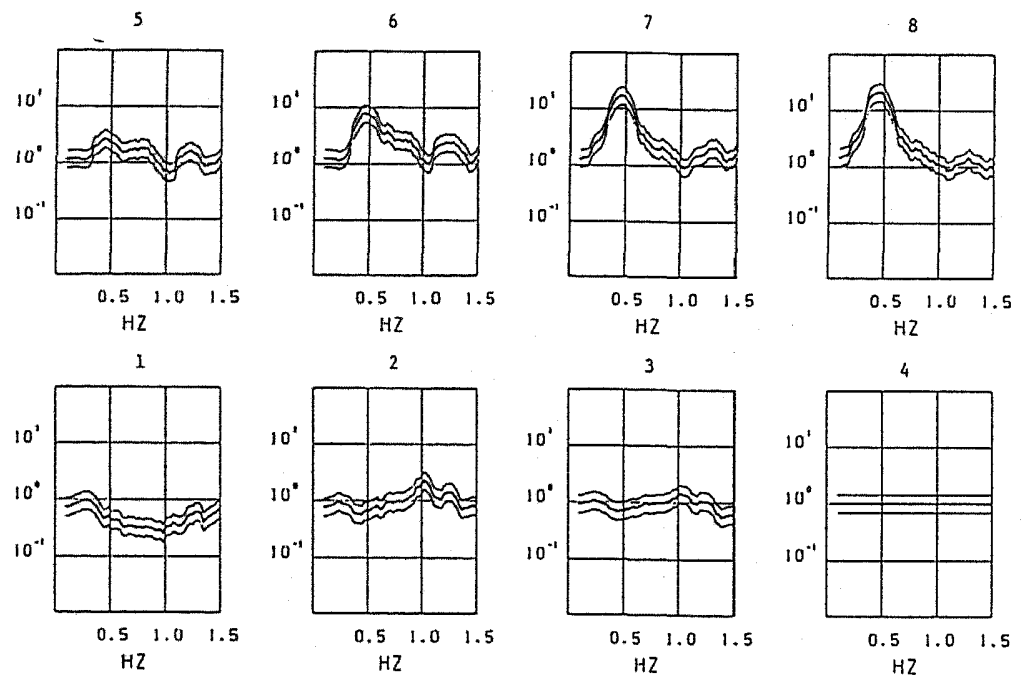

Fig. 2. Top: Measuring points of microtremors (solid circles) across the Kanegahara fault. Bottom: Spectral ratios of microtremors at every point to those at point 4 (NS-component). Amplitude ratios for $0.5 \mathrm{~Hz}$ at sites 5 through 8 are significantly large.

An array observation of microtremors to acquire data for inversion analysis was first attempted by Horike (1985). He clearly intended to discriminate surface waves from body waves to obtain the phase velocities of the surface waves which can be related with parameters of subsurface structure uniquely thus eliminating the source effects contaminated in microtremors spectra. He succeeded in inverting the data for propagational characteristics of a fundamental mode of Rayleigh waves at sites in south Osaka and south Kyoto, via frequency-wavenumber spectra, to corresponding 
subsurface structures up to 0.7 to $0.8 \mathrm{~km}$ depths (Fig. 3). A similar technique was applied at the south-east coast of Lake Biwa by Tsutsui and Kobayashi (1989). They used three arrays consisting of 5 vertical-type seismometers with the period of $7 \mathrm{~s}$ which cover areas over 0.5 to $1.0 \mathrm{~km}$ in diameter. No inversion was conducted but a trial-and-error approach was taken to reach a subsurface structure model attaining depths on the order of $1 \mathrm{~km}$. It was revealed through these applications that the analysis of frequencywavenumber spectra computed for array data is practically useful for inferring an approximate subsurface structure of an area. The application of array measurement has been so developed since then that even separation of Rayleigh and Love waves from a mixture of various types of waves is now realized (Okada and Matsushima, 1989).

\subsection{Refraction methods}

The refraction method is popular and there are many variations in its application. It is well known that in Japan a series of long-range explosions for refraction exploration have been conducted under a project over the country since the 1950's. This project has contributed greatly to elucidate the Earth's crust structure of this country. A series of refraction surveys conducted in the metropolitan area since the 1970's have also been useful to determine an approximate basement structure of the district (e.g., Yamanaka et al., 1988).

An explosion test that has been made in 1989 (Higashi, 1989) for the Ashigara Valley, the target area of the ESG study, is an example of the latter scale of exploration. Through this test the structure of the area up to the depth of $2 \mathrm{~km}$ was estimated, but it was naturally impossible to reveal a detailed structure on the order of some ten meters, since there were only three shot points and the intervals between stations were 200 to $500 \mathrm{~m}$. The length of the spread was more than $10 \mathrm{~km}$ and the intervals between shot points were about $5 \mathrm{~km}$.

A somewhat smaller scale example is an exploration in a reclaimed land in the southern part of the Kyoto Basin by Kitsunezaki et al. (1971). They conducted a refraction survey along a line traversing the site, and obtained the result that the basin, which is filled by Quaternary sediments, was about $700 \mathrm{~m}$ deep in its center and bounded both on the eastern and western sides by active faults. A profile with a typical vertical offset of the baserock due to faulting on its eastern margin, Obaku, is noted in Fig. 4. The average interval between geophones in this exploration was $50 \mathrm{~m}$. The total length of the spread was $12 \mathrm{~km}$ and the intervals between shots were 1.5 to $2 \mathrm{~km}$.

Kobayashi et al. (1980) conducted a more detailed refraction survey, which was far smaller in scale than that by Kitsunezaki et al. (1971), across the Obaku fault detected in the previous exploration using an airgun in a water-filled pit as a source apparatus. The average interval between geophones in this case was $10 \mathrm{~m}$ and the intervals between shot points were 50 to $100 \mathrm{~m}$. They determined the location of the fault more precisely than in the foregoing study.

\subsection{Reflection methods}

We will describe here three categories of reflection methods: classical method; Common-Depth-Point (CDP) method as a modern standard with multi-fold stacking; and Pseudo-Reflection Profiling (PRP) method developed by one of the authors (for

Vol. 40, No. 1, 1992 

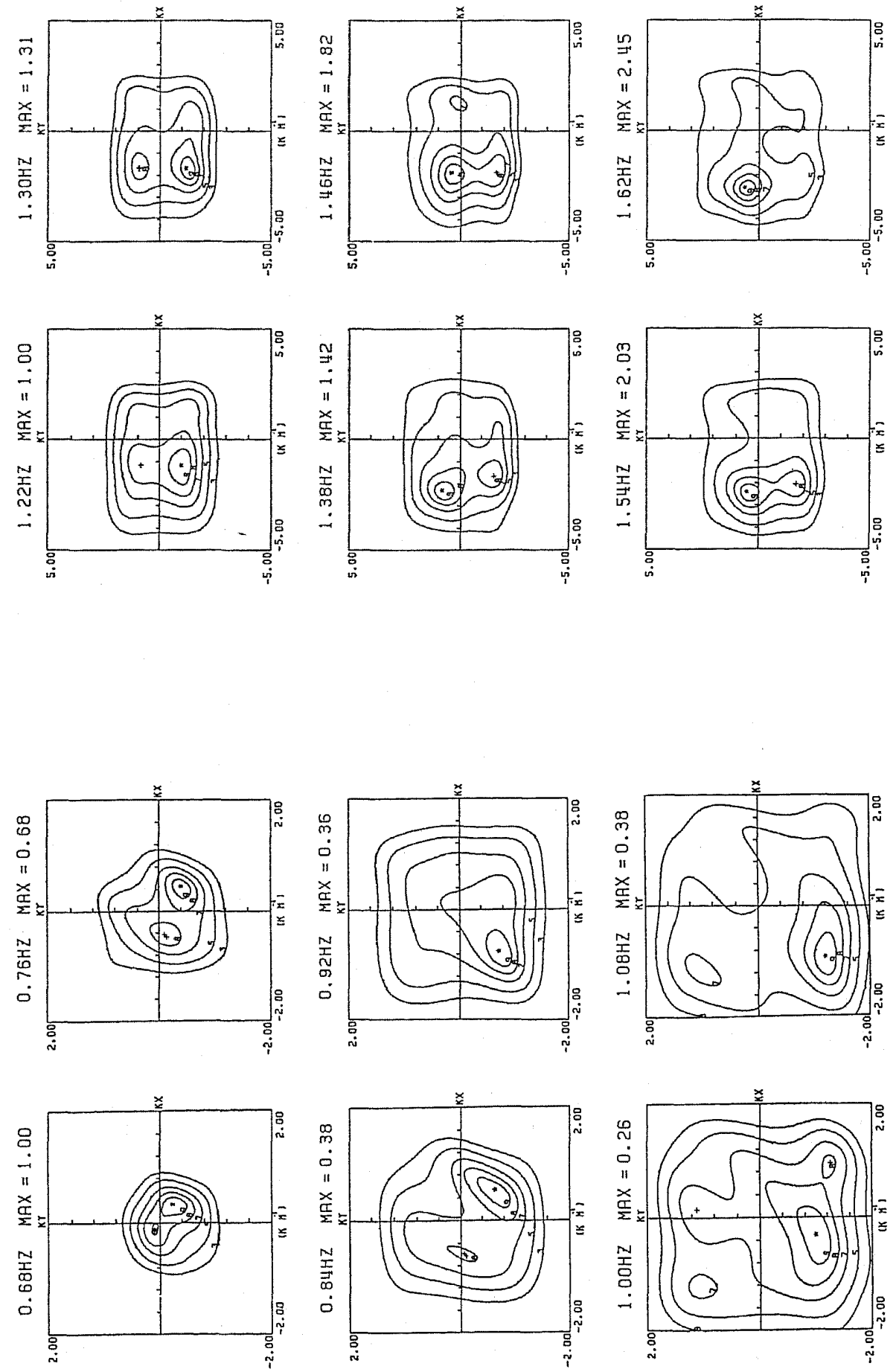

J. Phys. Earth 


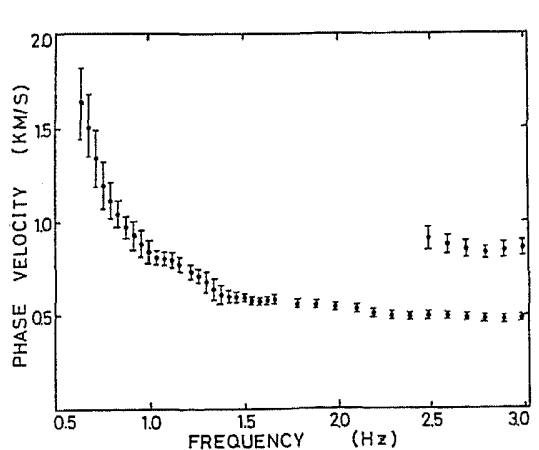

(b)

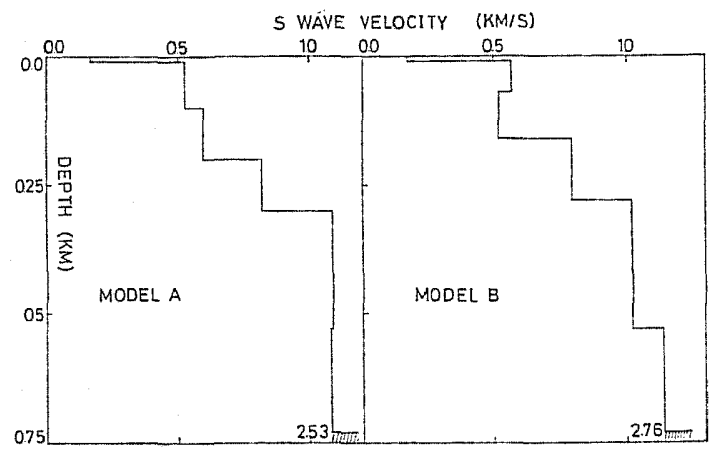

(c)

Fig. 3. Array method devised by Horike (1985). (a) Frequency-wavenumber spectra for frequencies 0.68 through $1.62 \mathrm{~Hz}$. (b) Phase velocities obtained from (a). (c) Inverted models A and B. Model A is obtained for the fundamental mode and B for the fundamental as well as higher modes of Rayleigh waves.
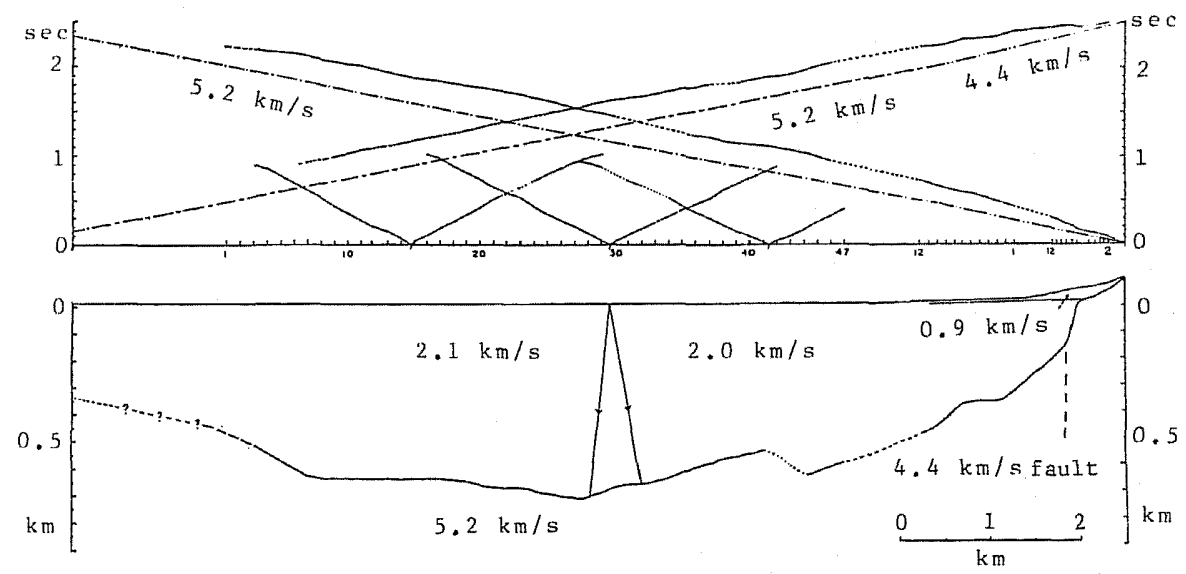

Fig. 4. Travel time curves and EW cross section of the Kyoto basin as revealed by seismic refraction survey. The abrupt change in depth of the bedrock on the right was caused by the Obaku fault (after Kitsunezaki et al., 1971).

the principle see Fig. 8 (a) and (b) and relevant descriptions).

The first example is the case at the Kanegahara fault on the western margin of the Kyoto Basin as cited in the section for microtremors measurement. After a series of geophysical investigations including gravity survey, microtremors measurements, and a small-scale CDP reflection survey whose penetration was only a little more than $100 \mathrm{~m}$, Kobayashi and Horike (1987) conducted a classical seismic reflection survey to explore deeper subsurface structure using an airgun submerged in water at 1 to $2 \mathrm{~m}$ depth below the surface as a source device (Bolt Par Air Gun, Model 600B, $40 \mathrm{cu}$.inch or $656 \mathrm{~cm}^{3}$ ).

Vol. 40, No. 1,1992 
(a)

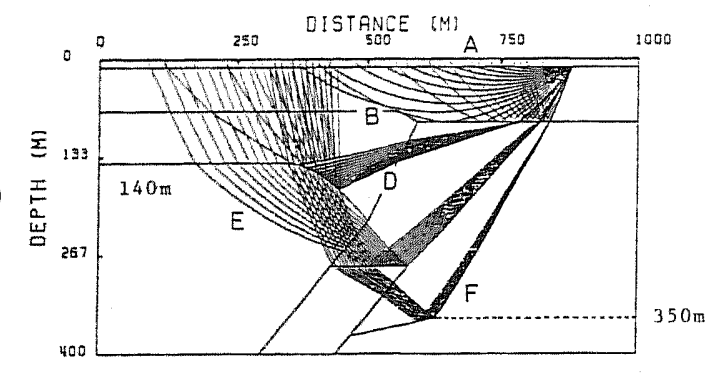

(b)

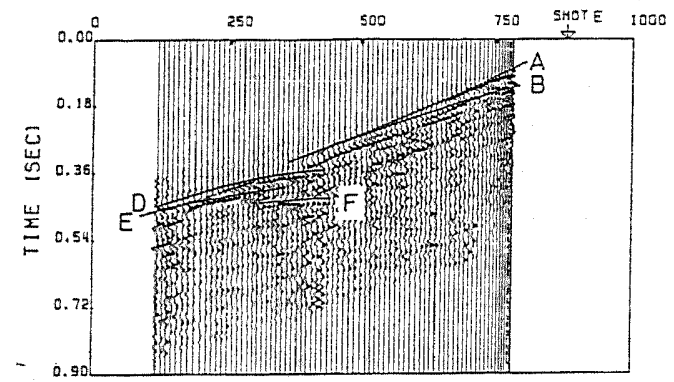

Fig. 5. (a) Example of ray tracing for the Kanegahara fault on the western bound of the Kyoto Basin with inferred subsurface structure. (b) Travel times for seismic rays shown above with observed seismograms for the east shot.

Geophones were placed on the embankment of Uji River. Restricted by hard access to the river side, they could set only two shot points on both ends of the measuring line as long as $700 \mathrm{~m}$. Geophone intervals were $10 \mathrm{~m}$. They derived a subsurface structure by adjusting the model so that synthetic seismograms by the ray method are satisfactorily similar to the measured ones. An example of ray tracing with the best fitting model is shown in Fig. 5.

Tsutsui et al. (1989) conducted a series of CDP reflection surveys on the southeastern coast of Lake Biwa to investigate subsurface around Hino River where buried faults were supposed to exist because there was a steep dip of Bouguer anomaly along the river, low on the west side. They used a hydraulic-driven impactor as a source device and obtained structures up to the depth of about $1 \mathrm{~km}$. Field parameters for data acquisition are given in Table 1 and an example of profile is shown in Fig. 6.

Tsutsui (1991) proposed a pseudo-reflection profiling method to produce time sections similar to those in the CDP method by using transmission seismograms on soft-deposit sites in long-range explosion tests. In an example conducted by him in the Hino River flat, the spread covered by this procedure was about $1.5 \mathrm{~km}$ in length and the intervals between stations were 50 to $100 \mathrm{~m}$ (Fig. 7). The principle of this method is shown schematically in Fig. 8 (a) and (b). It is based on the Claerbout-Kunetz equation (Claerbout, 1968) in a $z$-transform expression,

$$
(1+R(z)+R(1 / z)) \prod \mathrm{det}=X(z) X(1 / z)
$$

where $X(z)$ is transmitted impulse response, $R(z)$ is the corresponding reflection 
Table 1. Field parameters for the CDP surveys conducted in the south-east coast of Lake Biwa (Tsutsui et al., 1989).

\begin{tabular}{lcc}
\hline Survey line & Line $88-12$ & Line $87-10$ \\
\hline Total length & $1.0 \mathrm{~km}$ & $1.5 \mathrm{~km}$ \\
Shot point interval & $5 \mathrm{~m}$ & $10 \mathrm{~m}$ \\
Receiver interval & $10 \mathrm{~m}$ & $10 \mathrm{~m}$ \\
Recorded channels/shot & $4044 \mathrm{ch}$ & $48 \mathrm{ch}$ \\
CDP interval & $2.5 \mathrm{~m}$ & $5.0 \mathrm{~m}$ \\
Maximum fold number & 20 & 24 (major part), 10 (NE part) \\
Source device & Yuatsu-impactor & Dynasource \\
Receiver device & $30 \mathrm{~Hz} 6$-strings & $28 \mathrm{~Hz}$-strings \\
Data logger & DSS-10A system $\times 2$ (parallel operation) \\
Sampling interval & & $1 \mathrm{~ms}$ \\
Data length & & $2 \mathrm{~s}$ \\
\hline
\end{tabular}

Processing menu: Line 88-12 and Line 87-10 (major part): Sorting, Filtering, Deconvolution, Static correction, Velocity analysis, CDP stacking, and F-K migration. Line 87-10 (NE part): Sorting, Filtering, Deconvolution, Velocity analysis, and CDP stacking.

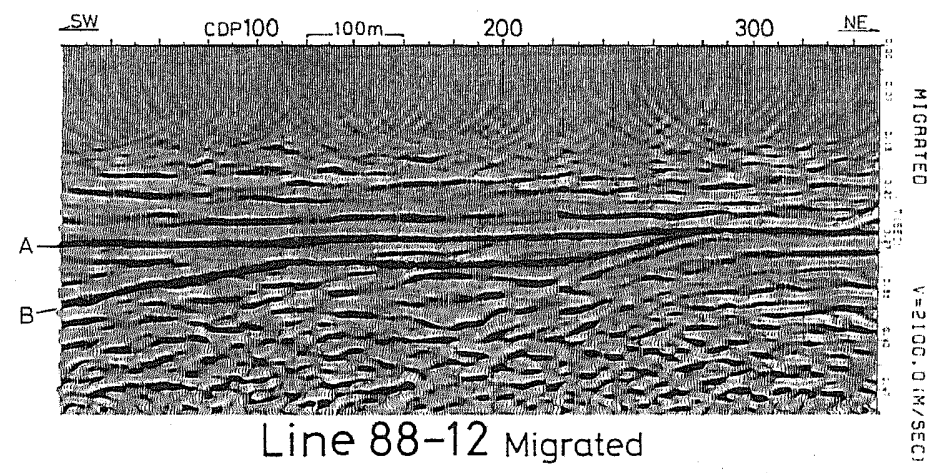

Fig. 6. CDP profile for the unconformity below Hino River site. A corresponds to a reflector in the Quaternary, and B to the granitic baserock (Tsutsui et al., 1989).

seismogram, and $\prod$ det is a constant. Thus the pseudo-reflection seismogram on a soft-deposit site may be derived from a transmitted impulse response $X_{i}(z)$ deconvolved from a seismogram $D_{i}(z)$ on the site with a reference wavelet $W(z)$ obtained at a near rock site. The details of the procedure are described elsewhere (Tsutsui, 1991). This method is efficient since it requires far less effort than the CDP method to cover a relatively wide area. Information on overall subsurface structure may be obtained relatively easily by designing the average station interval to be within the quarter of wavelengths of signal waves in the basement rock. 


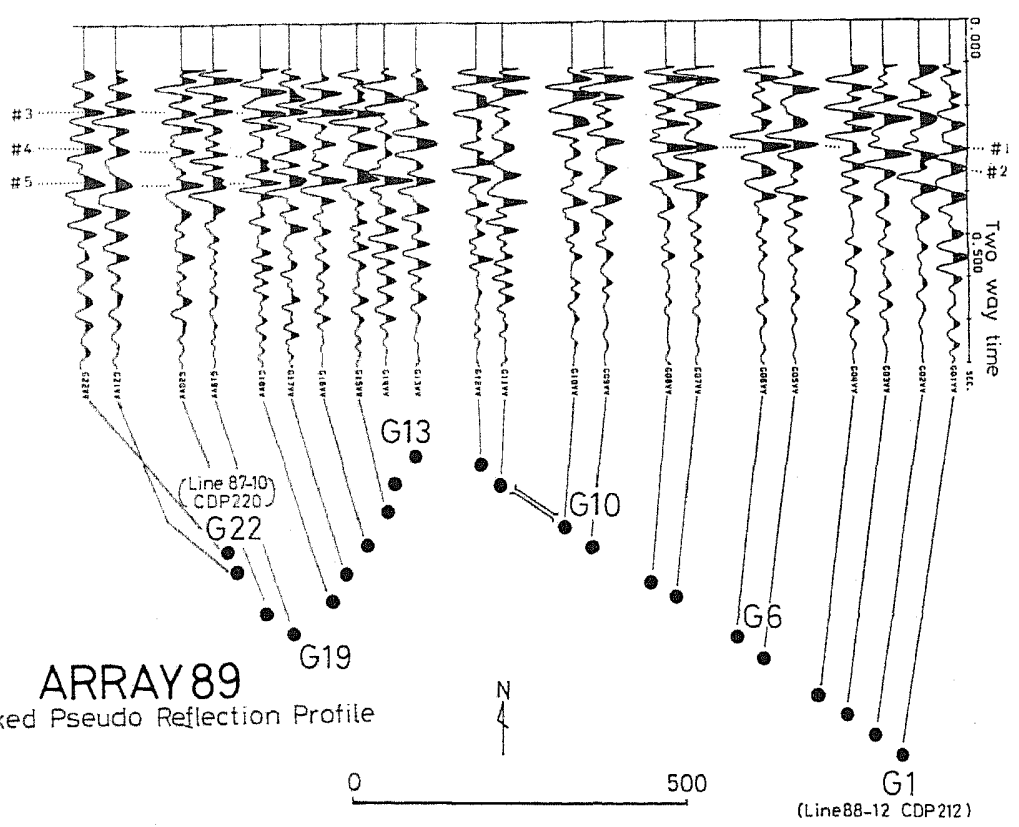

(a)

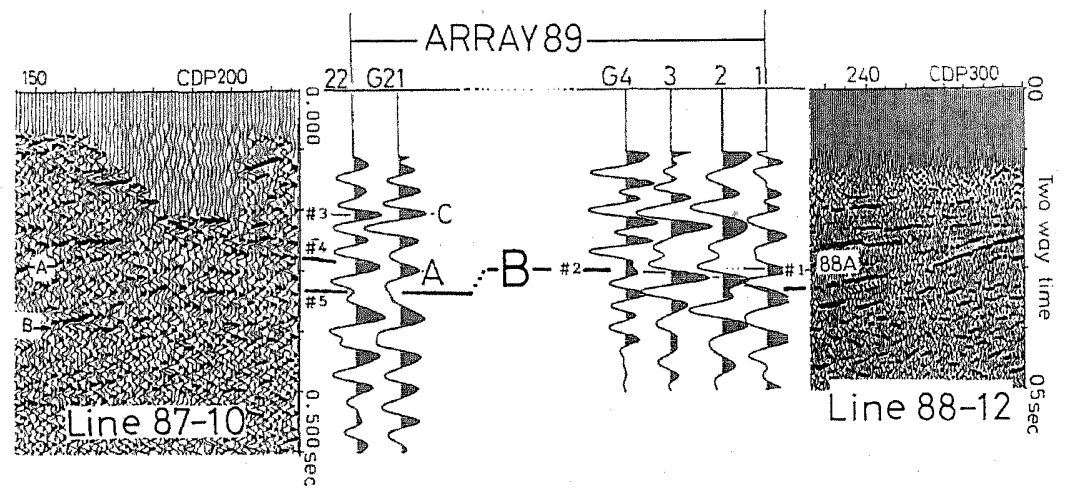

(b)

Fig. 7. Pseudo-reflection profiling method devised by Tsutsui (1991). (a) An example of pseudo-reflection profile over $1.5 \mathrm{~km}$ in the south-east coast of Lake Biwa. (b) Connection of phases in the pseudo-reflection profile to those in adjacent CDP profiles.

\section{Discussion}

We have classified the seismic exploration methods to determine subsurface structure into passive and active methods. The active methods include variations of 


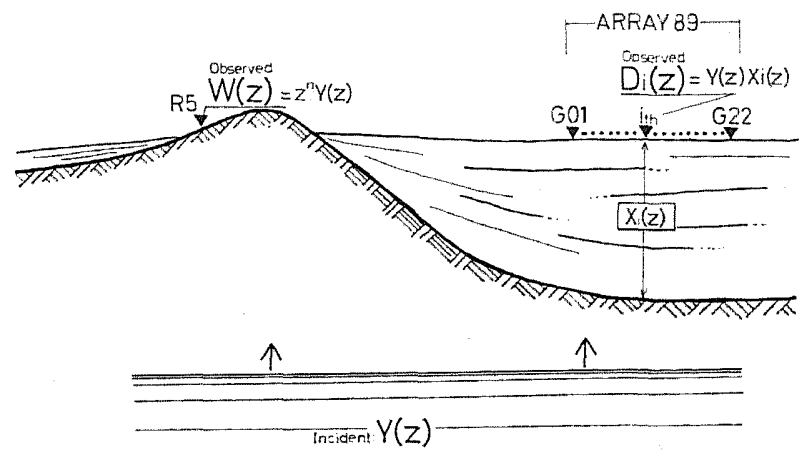

(a)

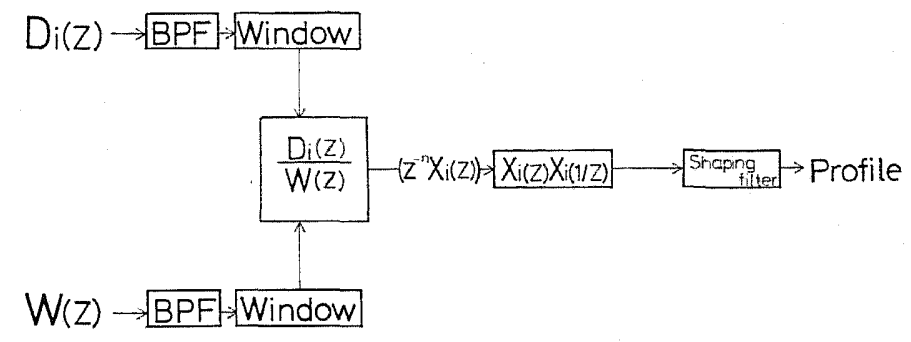

(b)

Fig. 8. (a) Illustration of scheme of pseudo-reflection profiling (PRP) method. (b) Flow diagram for computing pseudo-reflection seismograms through auto-correlations $X_{i}(z) X_{i}(1 / z)$ of transmitted impulse responses $X_{i}(z)$ deconvolved from records on soft deposit $D_{i}(z)$ with seismogram on the baserock $W(z)$.

seismic-refraction and reflection methods, and the passive methods include those of microtremors or microseisms measurements.

The use of microtremors or microseisms for subsurface structure exploration may be further divided into 1) measurements of their power spectra and 2) those of propagational characteristics by means of an array of seismometers. We call the former the power-spectra method and the latter frequency-wavenumber $(\mathrm{F}-\mathrm{K})$ method hereafter. In both methods, basically an identical type of seismometers may be used for measurements; however, the least necessary number of seismometers in a round of measurement can be naturally smaller for the power-spectra method than for the F-K method. But, even in the former, more than two seismometers are necessary for compensating for the effect of fluctuations of input spectra during a series of observations. It is accomplished by taking the spectral ratios between each station and a reference station. If only one seismometer is available some assumption for input motions becomes necessary, e.g., spectra of input motions are temporally stable and flat.

To infer the site characteristics from power spectra of microtremors, therefore, 
normalization of the spectra with those at a reference point is in general desirable to eliminate the effect of fluctuations of spectra of input motions with time. And, ratios of spectra at each point to those at a reference point during the same time section may be used instead of raw spectra. It has been shown that the ratio of power spectra follows the $\mathrm{F}$ distribution and the significance interval can be defined quantitatively (Aki and Richards, 1980; Jenkins and Watts, 1968). Thus, the validity of variations of the spectral ratios can be judged objectively with the aid of the significance interval.

The frequency-wavenumber method is preferable to the power-spectra method in that the propagational characteristics only are derived from microtremors' data. The data acquisition is, however, more laborious than the cases of power-spectra measurements, since every seismogram in an array must be lined up on a common time base. For instance, Horike (1985) used an array of 11 seismometers connected with cables laid over $1 \mathrm{~km}$ in diameter. Moriya (1986) recommends for array measurements to use independent stations equipped with a tape-recorder and a clock for time signal to avoid too much labor for extending cables over long distances. This method of array measurements will facilitate data acquisition appreciably, although data thus acquired with independent stations must be correlated to each other in laboratory using time information on individual records. This tedious work is an undesirable feature of this procedure. It is probable that this inconvenience will be eliminated in the near future with the development of technology.

Next, let us compare the merits and shortcomings of the refraction and reflection methods. The largest merit of the refraction method is that it provides reliable velocities information, while in the reflection methods they are just estimated from moveouts of slant-reflection phases from the corresponding vertical-reflection phase, and some additional surveys such as VSP or elaborate analyses such as pre-stack migration method (Sun and McMechan, 1986) are necessary for reliable velocities.

In contrast to the merit of the refraction method described above, there are some unfavorable features in normal practice of this method; to detect a refractor, a spread as long as at least, 5 times the depth to the refractor is necessary. The distance attenuation of head waves is stronger by 1 power of distance than that of reflected waves. From these reasons a longer spread and stronger shots tend to become necessary to survey a target depth than in a reflection survey of a comparable depth. These requirements are inefficient and can be a prohibiting factor in highly populated areas. Another unsatisfactory feature is its low vertical resolution. It is in general hard to detect interfaces in sediments unless they are especially sharp, and the method can be most practically used to explore a general structural feature such as configuration of the basement rock or other very sharp discontinuities in soft deposits.

Although the reflection method has normally some uncertainty in determining absolute velocities or absolute depths, it has a fair imaging capability of subsurface structure. This is a most favorable feature of this method because of its appealing power to pattern recognition. However, a survey with a modern standard reflection method, e.g., the common-depth-point method, is very elaborate and expensive compared to the refraction survey as in normal use. This sometimes makes it impossible to use the method in non-commercial geological studies.

The pseudo-reflection profiling method devised by Tsutsui (1991) is an appropriate 


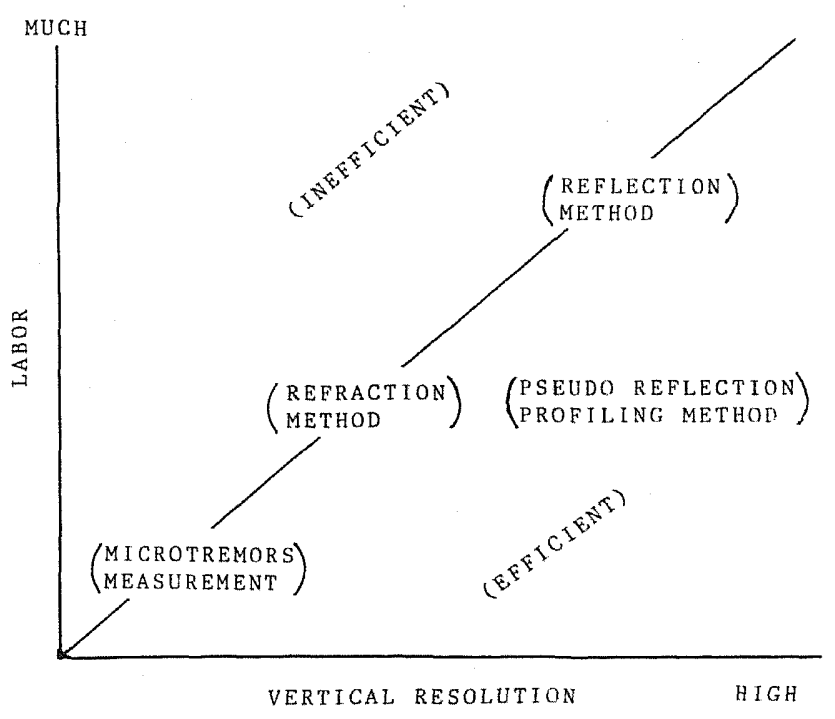

Fig. 9. Comparison of various seismic exploration methods in normal use in respect to average labor and vertical resolution. Methods in the right-lower triangle are more efficient than those in the left-higher triangle.

solution to this situation, since this has a similar character to the reflection method in imaging capability and is as economical as the refraction method. It has an important shortcoming, however, that it can provide neither velocities nor depths by itself. In order to obtain absolute depths, therefore, independent knowledge of velocities is necessary. It is therefore recommended that a CDP or Vertical-Seismic-Profiling (VSP) survey would be conducted in a part of a target area in conjunction with a PRP survey. If some phases in a pseudo-reflection profile are correlated to interfaces in CDP or VSP sections, those phases in the former may be interpreted.

The wave lengths we deal with in the seismic exploration methods in a broad sense cover those of microseisms (say several to some tens of kilometers) through those of active seismic methods (say some tens to hundreds of meters). A method employing longer wavelengths has naturally a lower resolution than that employing shorter wavelengths. In this respect, the microseisms measurement is inferior to the CDP method, etc. that uses short wave lengths. However, it is naturally unrealistic to apply the CDP method or other elaborate methods everywhere. Compared to reflection surveys, measurements of microtremors are substantially easy and therefore suitable to cover a large area quickly for reconnaissance purpose. A comparison of various methods in respect to average labor and resolution is given schematically in Fig. 9.

It should be reasonable therefore that we make microseisms measurement over a wide area first to seize an approximate subsurface structure and then apply a certain kind of active methods as a precise survey to a limited part of the area selected on the basis of the foregoing reconnaissance survey. It can be seen in Fig. 8 that the pseudo-reflection profiling method presented in this paper is relatively efficient and

Vol. 40, No. 1, 1992 
economical in surveying a large area with high vertical resolution and offers a new means of preliminary survey which is substantially useful compared to other existing reconnaissance survey methods.

We thank many colleagues who cooperated in explorations described in this paper. This series of research was supported in part by a project for Earthquake Prediction in the Kinki-Keihanshin area, Kyoto University, and that for Research of Major Active Faults in South-West Japan under the 5th and 6th Earthquake Prediction Program of Japan, respectively.

\section{REFERENCES}

Aki, K. and P. G. Richards, Quantitative Seismology, Freeman, San Francisco, Vol. 2, p. 603, 1980.

Claerbout, J. F., Synthesis of a layered medium from its acoustic transmission response, Geophysics, 33, 264-269, 1968.

Higashi, S., Underground structure beneath the Ashigara Valley, Japan, Proceedings of National Symposium on Effects of Surface Geology on Seismic Motion, 199-206, 1989.

Horike, M., Inversion of phase velocity of long-period microtremors to the S-wave-velocity structure down to the basement in urbanized areas, J. Phys. Earth, 33, 59-96, 1985.

Imazumi, T. and Y. Kobayashi, The Kanegahara tectonic line in the south-western part of the Kyoto basin as revealed by microtremor measurement and shallow seismic reflection method, Geophys. Explor., 38, 155-162, 1985 (in Japanese).

Irikura, K. and T. Kawanaka, Characteristics of microtremors on ground with discontinuous underground structure, Bull. Disas. Prev. Res. Inst., 30 (3), 81-96, 1980.

Jenkins, G. H. and D. G. Watts, Spectral Analysis and Its Applications, Holden-Day, San Francisco, 525 pp., 1968.

Kitsunezaki, C., N. Goto, and Y. Iwasaki, Underground structure of the southern part of the Kyoto basin obtained from seismic exploration and some related problems of earthquake engineering, Annu. Disas. Prev. Res. Inst., 14-A, 203-215, 1971 (in Japanese).

Kobayashi, Y. and M. Horike, Analysis of seismic exploration data using the ray method: Kanegahara fault structure near Kyoto, Japan, J. Phys. Earth, 35, 127-141, 1987.

Kobayashi, Y., K. Irikura, M. Horike, F. Amaike, K. Kishimoto, and S. Kasuga, Seismic exploration of the Obaku fault, Annu. Disas. Prev. Res. Inst., 23-B1, 95-106, 1980 (in Japanese).

Moriya, T., Data recorders for microtremors measurements and explosion tests, Reports for a Grant in Aid from the Ministry of Education and Culture, 59340026, ed. H. Okada, 99-104, 1986 (in Japanese).

Ohta, Y., H. Kagami, N. Goto, and K. Kudo, Observation of 1- to 5-second microtremors and their application to earthquake engineering. Part 1: Comparison with long-period accelerations at the Tokachi-oki earthquake of 1968, Bull. Seismol. Soc. Am., 68, 767-779, 1978.

Okada, H. and T. Matsushima, An exploration method using microtremors (1) - A theory to identify Love waves in microtremors-, Proceedings of 81 st Society of Exploration Geophysics of Japan Conference, 15-18, 1989 (in Japanese).

Research Group for Active Faults in Japan, Active Faults in Japan, the University of Tokyo Press, Tokyo, 363 pp.. 1980 (in Japanese).

Sun, R. and G. A. McMechan, Pre-stack reverse-time migration for elastic waves with application 
to synthetic offset vertical seismic profiles, Proceedings of IEEE, Vol. 74, 457-465, 1986.

Tsutsui, T., Pseudo-reflection profiling method: An efficient complement to CDP method, Geophys. Prospect., 39, 1991 (in press).

Tsutsui, T. and Y. Kobayashi, Discontinuity of basement rock depth in eastern coast of Lake Biwa discovered by observation of microseisms, J. Phys. Earth, 37, 133-146, 1989.

Tsutsui, T., Y. Kobayashi, Y. Shiba, Y. Suda, Y. Murai, T. Iwata, H. Fujiwara, and I. Matsui, Exploration of subsurface structure around the estuary of Hino River, southeast shore of Lake Biwa, by means of seismic reflection survey, Zisin II, 42, 405-418, 1989 (in Japanese).

Yamanaka, H., K. Seo, T, Samano, S. Midorikawa, E. Shima, and M. Yanagisawa, On the seismic prospecting in the southwestern part of the Tokyo metropolitan area (3), Zisin II, 41, 527-539, 1988 (in Japanese). 